\title{
Discussion on the Creative Fashion Design Extended from Clothing Technology
}

\author{
WU Yujun \\ Institute of Clothing Technology, Chengdu Textile College, Chengdu 611731, Sichuan, China
}

Keywords: Clothing Technology; Process Reconstruction; Fabric Reconstruction; Creative Design

\begin{abstract}
In this paper, the author studied the guidance and creativity from the clothing technology design to creative fashion style design in terms of process reconstruction and material application by decomposing the processing technology of clothing parts and analyzing the style creativity, with taking the case of the designs for six non-conventional pockets. The controllability and efficiency from the implementation of stitch process change, auxiliary material creativity, and fabric pre-processing/transformation/design in the process design to the style design were analyzed, and then the style design elements were comprehensively extended from the perspective of process design. Also, the inter-relationship between the fashion style and clothing technology was deconstructed; new design elements inspired by material transformation, processing method, and process decomposition were explored. Finally, the reversal fashion design flow was proposed — creative design was inspired by process design to lead another expandable design idea for fashion style design.
\end{abstract}

\section{Introduction}

Generally, fashion design is understood as an art of modelling, in which a recreation of both art and technology is made through artistic conception according to the laws of beauty and the application of many elements such as shape, color, and fabrics, aiming to create an external art image that is superior to ordinary things and can produce a substantive visual effect. Specifically, it is classified into clothing style design, clothing structure design, and clothing process design. According to the conventional and forward clothing production flow, clothing processing design is often a process after the completion of clothing style design, and therefore, it is unable to get involved into the earlier style design in terms of the process implementation, but usually follows and completely reflects the style. Fashion means change, so designers need to maintain an unceasing power for creations by constantly getting rid of the innovation pressure. In the current numerous and complicated fashion designs, many starting points for creative design ideas are discovered, which are comprehensions and innovations for process design, but not confined to the scope of the traditional design.

\section{Creative design for the decomposition technology of clothing parts}

Pocket design and process reconstruction. Conventional pocket design for ready-made clothes was mainly classified into patch pocket, slant pocket, and welt pocket and so on. The designs for the appearance of pockets were diversified, but required to be consistent with the style of ready-made clothes in forms. The design for welt pocket was taken for example: the common styles included single-welt pockets and double-welt pockets; ordinary shape change was divided into the change of pocket length and the change of welt width. Split process was required to be accurate and consistent with the pocket width, for letting pockets look elegant. On the unsewn cloth, the length of the part for the welt pocket was usually fit with the length of the pocket: if it was greater than the length of the pocket, the intersection between upper and lower welts would generate a style of knotted welts-knotted decorative, double-welt pocket, as shown in Fig.1. In the production process, the separation and combined knotting of welt cloth would appear, and the shape after the separation of welt seams became another bright design spot. 


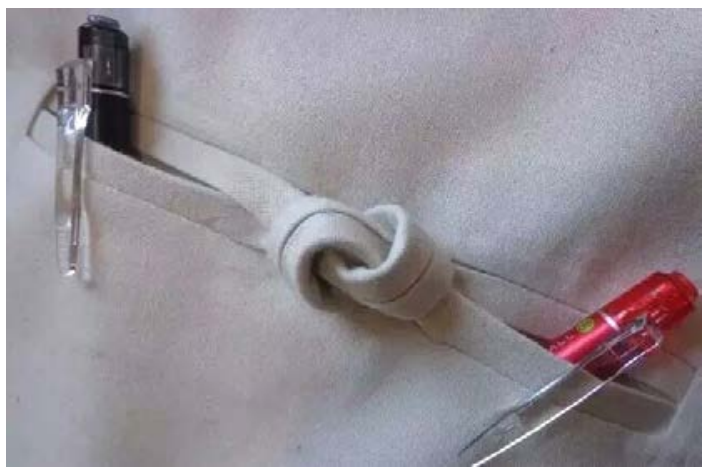

Fig.1 knotted decorative, double-welt pocket

Welt pocket was often designed in a form of straight slit pocket, in which arc design process was with some difficulties, but could play a better visual effect. As shown in Fig.2, the arc slit pocket design with double-arc, separate welts was more challengeable from both technology and process. Additionally, the shape of welts was distinctively hierarchical and streaky; assorted colors were applied to slit pocket cloth, making the shape of the pocket remarkable and beautiful.

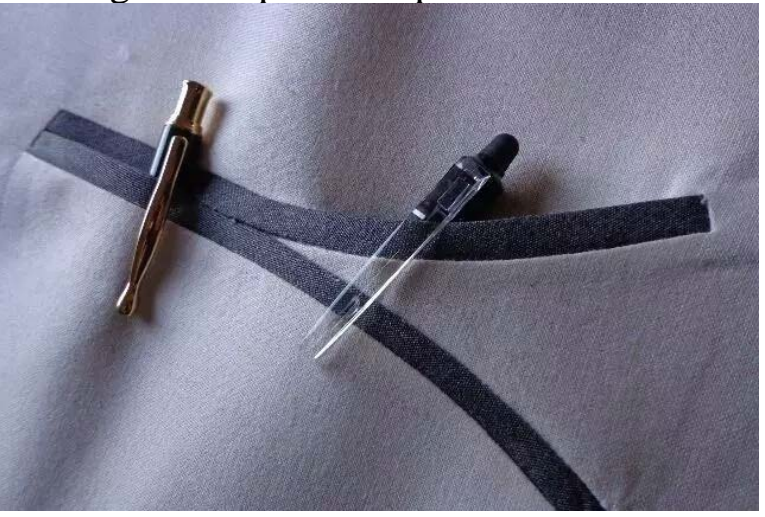

Fig.2 double-arc, separate welt pocket

On pocket decorations, fit strips, trim strips and mixed strips could play different exhibition effects; as shown in Fig.3, the implementation of the process for knotted, superimposed decorative artistic pocket demanded a three-dimensional morphological analysis on three knots of both sides; the pocket mouth was composed of six independent manually-spliced strips. Designers needed to know well the implementation process from the three-dimensional shape of the pocket mouth, before they were integrated into the design idea to improve the shape.

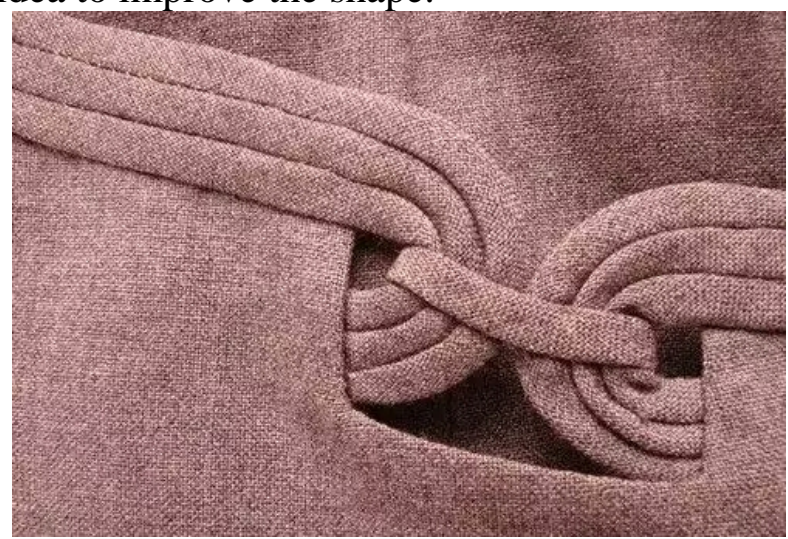

Fig.3 knotted, superimposed decorative artistic pocket

The processes for the mouths of bags and suitcases were diversified. On the processes, the rigidness and stylish effect of the materials were emphasized. This characteristic fit with the fabrics if it was integrated with the clothing pocket design, as shown in Fig.4-three-dimensional box-type pocket (closed), and Fig.5-three-dimensional box-type pocket (opening). In these designs, the opening shapes of bags and suitcases were fully introduced, in which welt pocket process and patch pocket process were combined, and simultaneously the topstitching ways for bags and suitcases were used for reference. 


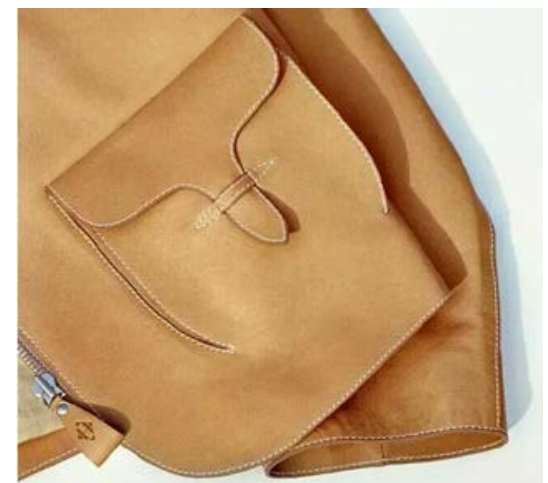

Fig.4 three-dimensional box-type pocket (closed)

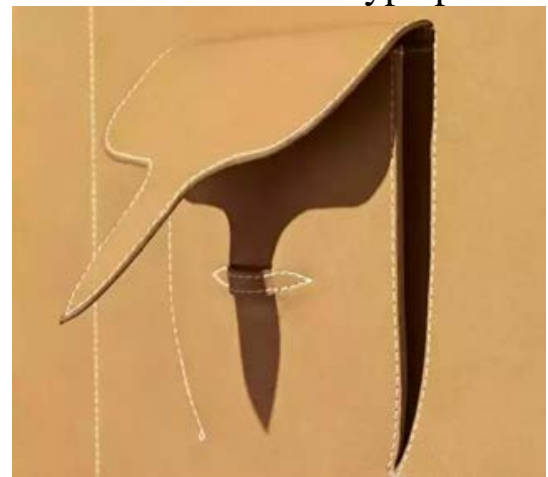

Fig.5 three-dimensional box-type pocket (opening)

The above four pocket designs looked distinguishing in their styles, but the starting points in these designs were divorced from ordinary pocket formative technology — a breakthrough was sought in the pocket production process: the change of process change was integrated with shape; these exquisite pocket designs would never be achieved if designers did not know well the pocket processes.

The application of auxiliary materials to pocket process. There were also many common understandings between clothing pocket parts and bag/suitcase design; in design of luggage, there was often a design of expansion layer to adjust the volume by the closing and opening of zippers, thus letting the loading volume of luggage expanded by more than $20 \%$. As shown in Fig.6, the sides of expanded zipper box-type pocket added the volume using the closing and opening of zippers; on the process design, the luggage processing way was introduced, making the pocket artistic and highlighted. The pocket with a clip mouth was a common form of vintage pockets; in fashion design, a closing function was often seldom designed for the mouth of pockets; as shown in Fig.7, the autonomous, flexible and convenient use of clip was realized in the form of the clip mouth of pocket.

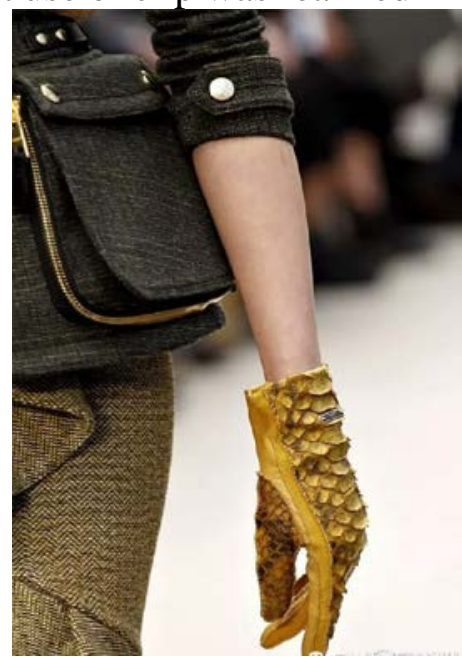

Fig.6 box-type pocket with expanding zipper 


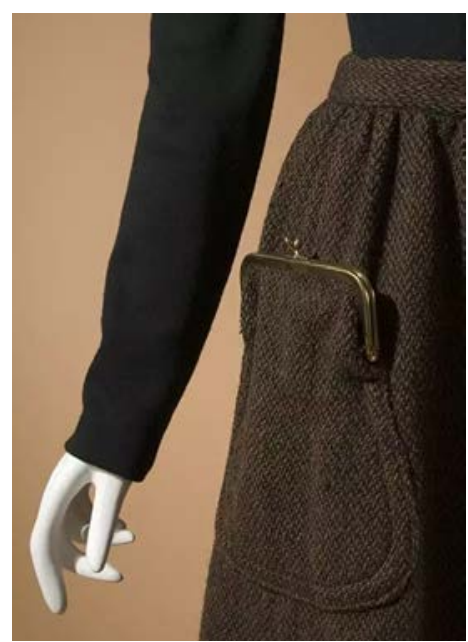

Fig.7 pocket with clip mouth

In the common auxiliary materials for pockets, zipper, magic stick, and studs were in the majority; for fulfilling the convenience and quickness of the mouth, the applied parts and functionality could play many creative effects. Pocket designs in Fig.6 and Fig.7 flexibly used the functional elements in the bag/suitcase design for reference, so that the designs looked fresh and new in both details and functions.

\section{The action of process design on style creativity}

Process design always invisibly played a decisive role in each style design; mature designers deeply understood that the effective implementation of styles was contained in the subtle processing methods of many processes [1]. A customized jacket overall required fitting with the body, and therefore, usually a variety of subtle style changes were often available for collars, revers, shoulder lines, and bottom margins; the structure of sleeves could be one or two pieces of sleeves; for front fly, single-breasted or double-breasted styles could be designed, but excellent designers would consider more elements. Supports in the stitching process were often available for the jacket combined with several different cut pieces, so as to ensure the stability of a welt pocket slant inserted between front piece and side piece and then use it as the prerequisite of style design [2]. Obviously, a style, which could be implemented in process design, naturally became a combined creative idea with process design in fashion style design.

Processing technology and style. From the perspective of extended thinking, creative ideas influencing the design could be produced from the combined clothing processes including parts and sewing effects, when process design not only played a splicing and combination role in some parts of clothing. Many processes containing clothing processing technologies could generate a lot of decorative effects in forms; needle tracking, stitches, binding, edges, inlays, gilding, twisting, embroidering, and other processes could present different fashion styles through line decorations. For example, whipstitch could show the special effects of the deckle edges of fabrics; topstitching could produce a decorative effect of lines; binding could sketch the contours of the seam allowance of clothing; elastic cord could let fabrics present finely pleated puckers. All these processes could be regarded as the elements of fashion design.

Fabric transformation and modelling. Fabric transformation is a frequently-used design method at present, in which the creative design and processing of the original fabrics are implemented using various traditional and high-tech means to let it change the original fabric forms and superficially produce different visual and tactile textures [3]. Fabric recreation art can not only increase the added values of clothing products, but also can let customers feel fresh about the external forms of clothing [4]. There are many methods for fabric transformation to mainly design the early processing of fabric appearance. The common methods such as folding, weaving, shrinking, goffering, stacking, and pleating could make the external size of fabrics change, so as to generate the concave and convex texture contrasts and different touch feelings. Also, fabrics could be combined and processed using 
different fiber materials, and plentiful rhythmic levels were reconstructed through knitting, hook junction, and other methods to convert the flat materials into three-dimensional relief-alike feelings [5].

When pleating technology was comprehensively applied to a dress, the integration of process design with structure design jointly controlled the overall shape; as shown in Fig.8, in the pleated fabric design, the transformation of many fabrics was a source of the inspiration for clothing creativity; when the process made the fabrics change, clothing structure and shape were required to cooperate with the process for presenting the overall clothing design characteristics; the early creative inspirations were naturally transformed as aids from the process change.

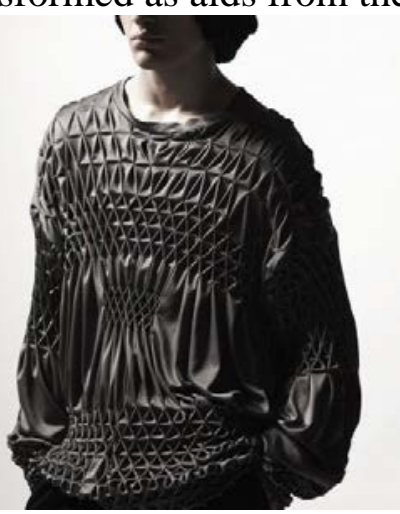

Fig.8 pleated fabric design

In the current fabric transformation, new technologies are used for making more breakthroughs [6]. In the process expressing techniques and fabric post-processing technologies, new equipment and technology are used for implementing the modern technologies such as anhydrous textile printing, intelligent embroidery, computer weaving machine, computer jet printing, and digital printing [7]. For example, pleated fabric processing is a fabric post-processing technology to form thermally-deformed pleats. The redesign of the fabrics processed with hot-pressing technology is another creative form. As shown in Fig.9, the early process infiltration of Issey Miyake pleats design played a direct influence on the design again. Issey Miyake, Japan's famous fashion designer, was reputable in the world because of his extremely high process innovation; he discovered the source of vitality of fashion design by differing from the western clothing design ideas, sought for the beauties of new clothing functions, forms, and decorations from the eastern clothing culture and philosophies, devoted himself to the integration of fabrics into fashion design, and finally designed unprecedented new concept clothing works [8].

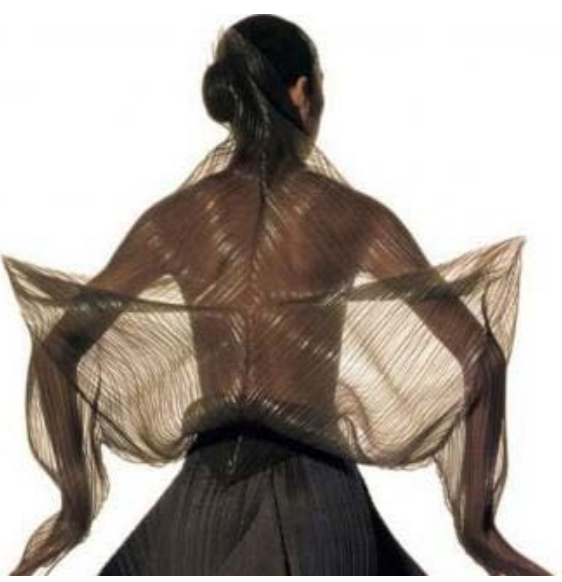

Fig.9 Issey Miyake pleats design

During the fabric reconstruction, designers were no longer passive to be engaged in the operations, but converted the making process into creative activities such as repeatedly transforming the flow and absorbing and creating some new production methods, thus manifesting their own unique expressive language [9].

Material design was rooted in the beginning of process design, requiring designers to understand and play the material changes using the creation of process. The traditional Chinese material 
transformation was mainly handmade embroidery on lappet, chest, back, and cuff; on the flat materials, the traditional craft techniques such as embroidering, patching, and cross-stitch were used for sewing the patterns with symbolism so as to show the change of layers in the appearance. When technology became richer and updated along with the development of the times, the fabric transformation and production means would gradually break away from the traditional process methods such as knitting, binding, and embroidery. As fashion got rich and innovative, many processing methods and technologies such as winding, parceling, paste, quilting seam, folding, accumulation, inlay, knot, covering, overlapping, hollow-out, embossing, carve patterns and burning would generate more rich styles and external effects [10]. Now, the development of clothing equipment could fulfill the implementation of more diversified styles. For example, leather carving, hot pressing, plant fiber spices, and a combination of poly-type materials could form special aesthetic feelings.

\section{Process application and modeling for parts of clothing}

Designers usually took the production process effect into consideration in the style design and would reflect in the design; as shown in Fig.10, the processing for the beam knot collar improved the point for the designed style. In Fig.11, in the buckle design for the shoulder of side buckle shawl collar, a scarf collar style was formed through fixation. Thus, an understanding of technology was closely related to style design: the integration of process design into details could not only generate rich styles, but also increase the functions of clothing. The connection forms such as nail catcher, zipper, and ropes in clothing would play a different effect in terms of the appearance.

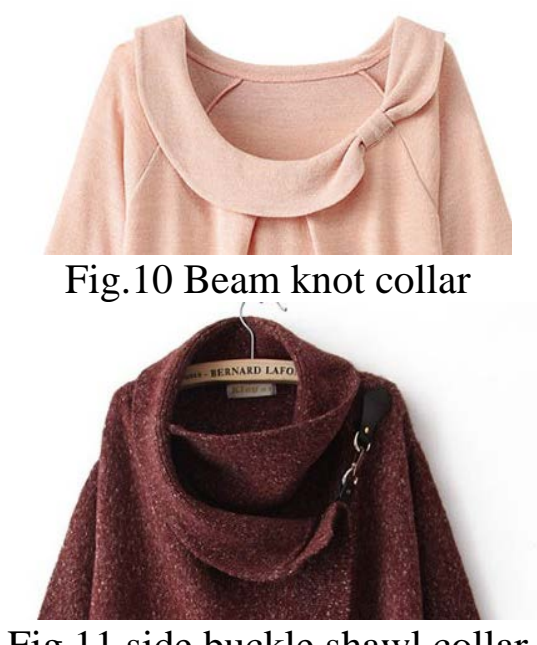

Fig.11 side buckle shawl collar

\section{Conclusion}

Designers lay an emphasis on the fashionable trends, styles, and fabrics for the goal of carefully managing the themes of every season. It is true that conventional design process is the mainstream trend. However, many designers lightly processed the process of detail designs, thus ignoring the detail structure in design - this meant the process design ways inspiring creative ideas might be ignored. Fashion designers need to use the reverse design process for reference properly and understand the details and skills in process design, in order to update the clothing plate-making technology and then comprehensively extend the style design elements from the perspective of process design. Thus, the interaction between fashion style and process will be better reconstructed; infinite design elements such as material transformation, processing methods, and process decomposition will be explored. 


\section{References}

[1] DAI Lu. Application of Detail Design in the Garment Modeling [J]. Journal of Textile Research, 2012 (7):119-121.

[2] [British] McKelvey, [British] Munslow. Fashion design: The Process of Innovation and Practice (Ed. 2) [M]. China textile press, 2014: 75-79.

[3] CHE Weidong, JIN Changying, Artistic performance of Fabric Recreation in Fashion Design [J]. China Textile Leader, 2011(6): 96-97.

[4] ZHU Yan, Practical Significance of Fabric Reengineering Technique upon Costume Designers [J]. Hundred Schools in Arts, 2011(2): 232-233.

[5] WENG Xiaochuan. Clothing Material in the Design of Innovative Applications Research [D]. Shanghai: Donghua University, 2014: 21-28.

[6] Zong Min. Discussion about the Details of Women's Clothing in the Design of Fabric Design and Innovation [D]. China Academy of Art, 2012: 9-20.

[7] XIAO Qiongqiong. Discussion on the Design View Point and Method of Apparel Detail [J]. Arts Criticism, 2010 (6):112-114.

[8] WEI Yingkai, QIAO Mei. Apparel Fabrics in Design of Reengineering Research [J]. Guangxi Journal of Light Industry, 2008 (5): 86-87.

[9] YIN Yanmei, ZHU Hanyu, XU linjian. The Application of Clothing Handicrafts in the Knitwear Design [J]. Journal of Zhejiang University of Technology, 2010, 27 (1): 84-88.

[10] FAN Juhong. Application of Decoration Technology in Fashion Design [J], Journal of Zhengzhou Institute of Light Industry (Social Science Edition), 2005 (6): 34-36.

\section{Introduction to the Author}

WU Yujun (1980- ), female, born in Chengdu, Sichuan province, attaining a master degree, is a college lecturer now. She is dedicated to studying clothing engineering. 